\title{
Atenção integral à saúde de mulheres em situação de violência de gênero - uma alternativa para a atenção primária em saúde
}

\author{
Comprehensive health (care) services to women \\ in gender violence situation - an alternative to primary health care
}

Ana Flávia Pires Lucas d Oliveira $^{1}$

Lilia Blima Schraiber ${ }^{1}$

Heloisa $\mathrm{H}_{\text {anada }}{ }^{1}$

Julia Durand ${ }^{1}$

${ }^{1}$ Departamento de

Medicina Preventiva,

Faculdadede M edicina,

Universidade de São Paulo.

Av. Dr. Arnaldo 455/2.245,

Cerqueira César.

01246-903 São Paulo SP.

vawbr@usp.br
Abstract This paper deals with the possibilities of the health sector to approach violence against women in its practices as a gender issue. It is presented a conceptual and theoretical comprehension of gender violence linked to a care proposal, as the definition of the problem is essential to the intervention, answering to different social ends. To do that, is necessary to think what the objectives of the work in health are and where it is placed within the production and reproduction of the ways of living and falling ill. It is argued the possi bility of full assistance, in order that violence itself, and not only its repercussions, are considered in the health work. The proposal of care for sexual violence in Brazil is recovered, and a model of primary health care implemented at Samuel B. Pessoa H ealth School Center is presented. This model is integrated in the Women's Integral H ealth Care Program (PAISM ) and attends women in severe domestic conflicts (CON FAD) conceptualized as a specific technique of detection, listening and counseling, featuring a "chat technique" as a professional action. To conclude, aspects related to the connections of the health sector with the intersectorial network are discussed presenting its principal difficulties.

Key words Primary health care, Domestic violence, Violence against women, Intimate partner violence, Women's health services
Resumo Esteartigo trata das possibilidades de atuação do campo da saúdena abordagem da violência contra a mulher desde suas práticas assistenciais nos serviços e baseadas na perspectiva de gênero. Apre senta-se uma dada compreensão teórico conceitual da violência de gênero contra as mulheres articulada a uma proposta de cuidado, pois a forma como 0 problema é delimitado é essencial para a intervenção, respondendo a finalidades sociais diversas. Trata-se, portanto, de pensar quais os objetivos da ação em saúde e qual o seu lugar na produção e reprodução demodos de viver eadoecer. D efende-sea possibilidade de atendimento integral, para que também a violência, enão apenas suas repercussões, seja considerada no trabalho em saúde. Recupera-se a proposta de atenção dirigida à violência sexual no Brasil e debate-se uma possibilidade de atuação na atenção primária tal como implantada no Centro de Saúde Escola Samuel B. Pessoa. As ações propostas e integradas ao Programa de A tenção Integral à Saúde da Mulher (PAISM) da Unidade constituem uma atividade de atendimentos a conflitos familiares difíceis (CONFAD), conceituada como uma técnica específica de detecção, escuta eorientação qualificadas, que caracterizam uma "técnica de conversa" como agir profissional. Por fim, discutem-se aspectos relativosà conexão do setor saúde com a rede intersetorial de atenção e suas principais dificuldades.

Palavras-chave Atenção primaria à saúde, Violência doméstica, Violência contra a mulher, Violência por parceiro íntimo, Serviços de saúde para mulheres 
Introdução

Este artigo trata de alternativas para o trabal ho na saúde, em especial na atenção básica, ou primária, ao se tomar a violência de gênero contra a mulher como alvo de suas práticas. Está baseado em catorze anos de experiência do Grupo de Pesquisa e Intervenção Violência e Gênero nas Práticas de Saúde (Departamento de M edicina Preventiva/FM USP) em lidar com capacitação e supervisão dos profissionais de saúdena temática da violência doméstica e sexual contra a mulher; criação e implementação de uma tecnologia específica de cuidado às mulheres em situação de violência para aten ção primária; e formação e aprimoramento de redes de cuidados no Distrito Escola do Butantã, Zona O este de São Paulo, objetivando uma atuação intersetorial local.

Busca-se basear a intervenção em foco nos estudos teóricos e empíricos produzidos sobre o tema, tanto de escopo nacional quanto internacional, tomando-se, portanto, no que tange à violência, a gênero e ao trabalho em saúde, um quadro teórico referencial e uma determinada definição conceitual da violência de gênero.

A violência contra a mulher passa a ser tema de estudo e interven ção na área da saúde a partir dos anos noventa, ao mesmo tempo em que se firma internacionalmente como questão de direitos humanos $^{1}$. Decorridos já seis anos do relatório da OM S sobre violência e saúde², torna-se conhecido para os profissionais de saúde o fato de que a violência contra a mulher tem alta magnitude e relevância na saúde. Sabe-se já que mulheres que vivem/viveram violência doméstica esexual têm mais queixas, distúrbios e patologias, físicos e mentais, e utilizam os serviços de saúde com maior frequência do que aquelas sem esta experiência ${ }^{3}$. As mulheres podem apresentar-se a serviços de urgência e emergência por problemas decorrentes diretamente da violência física ou sexual (traumas, fraturas, tentativas desuicídio, abortamentos, etc.) ou recorrer a serviços de atenção primária em decorrência de sofrimentos pouco específicos, doenças crônicas, agravos à saúde reprodutiva e sexual ou transtornos mentais que ocorrem em maior frequência nestes casos ${ }^{4}$. Ações preventivas, paradoxalmente, são menos utilizadas por estas muIheres, tendo elas menores chances de realizarem 0 Papanicolaou ${ }^{5}$ ou utilizarem condom ${ }^{6}$.

No entanto, este uso do serviço, ainda que frequente, épouco resolutivo. Da perspectiva dos profissionais, estes casos tornam-se motivo de frustração e impotência ${ }^{7}$, e, da perspectiva do sistema de saúde, uma demanda que gera al tos custos com resultados muito pouco efetivos.
Mas o que os serviços de saúde podem fazer em relação ao problema? Qual seria o seu papel específico no cuidado à questão? Seria a violência realmente uma questão de saúde ou os serviços deveriam apenas tratar as consequências de sua ocorrência?

As respostas nesse caso não são simples. Internacionalmente, especialmentenos Estados Unidos e Canadá, a estratégia mais propagada é a do rastreamento de violência doméstica para todas as usuárias, dada a enorme prevalência do problema (em torno de um terço a metade das mulheres) ea falta de fatores de risco bem configurados e preditores dos casos. No entanto, esta proposta, ainda que bastante divulgada e implantada em diversos serviços, ainda que promova al gum tipo de visibilidade da violência, tem apresentado baixa adesão dos profissionais e pouca consolidação nos serviços, por diversos motivos. A discussão na literatura é grande, levantando, além da baixa adesão, a inexistência de avaliações que comprovem a inocuidade da estratégia eespecialmente sua efetividade, em termos das medidas tomadas a partir da identificação dos casos, condições necessárias para a recomendação de um screening universal ${ }^{8,9}$.

Por outro lado, uma grande parte das interven ções realizadas rotineiramente para outros problemas de saúde não são sustentadas por evidências científicas ea violência de gênero é muito prevalente e tem graves consequências para a saúde. Argumenta-se que a pergunta a princípio teria pouco potencial de causar algum dano, o que sustentaria a proposta de busca ativa de rotina enquanto não são produzidas evidências científicas que tragam maiores informações ${ }^{9}$.

À identificação segue-se, na maioria dos protocolos, propostas do registro adequado, do estímulo ao trabal ho em equipe, da garantia de sigilo e privacidade e do acionamento da rede intersetorial existente, garantindo-se os princípios de não julgamento e respeito às decisões da mulher.

Uma recente revisão das estratégias utilizadas pelos países de renda média ou baixa na saúde ${ }^{10}$ mostra a organização de serviços baseados em hospitais secundários ou terciários e também em unidades de atenção primária, mas com grandes desafios na articulação entre eles e com a rede intersetorial. Alguns serviços, especialmente os hospitalares no modelo one stop crisis center, incluem também a assistência jurídica epolicial no mesmo local. Outros trabal ham com referenciamento, mas ainda são poucos os modelos e raras as avaliações, não havendo consensos estabelecidos, com prós e contras para cada uma das possibilidades apresentadas. A articulação, seja interna à saúde, seja 
com a rede intersetorial, ainda é bastante rara e incipiente.

Qual deveria então ser a atuação dos serviços de saúde em um país como o Brasil? 0 que podem eles fazer para detectar e, ainda mais crítico, trabaIhar os casos de violência além daquilo que já fazem, ou seja, tratar as patologias decorrentes? E seria isto necessário e factível?

Queremos defender aqui que a forma como compreendemos e delimitamos o problema a ser trabalhado é essencial para a intervenção, já que para cada definição do que venha a ser violência e qual a sua relação com a saúde, uma determinada interven ção é proposta e realizada, respondendo a finalidades sociais diversas. Trata-se, portanto, de pensar quais os objetivos da ação em saúde e qual o seu lugar na produção e reprodução de modos de viver e adoecer, com as crenças, valores e atitudes culturalmente dado na saúde e na sociedade brasileira de modo geral.

0 uso reiterado e ineficaz dos serviços de saúde, tanto de urgência e emergência como de atenção primária, decorre, a nosso ver, da redução do problema às suas manifestações no corpo entendido da perspectiva biomédica, e da consequente invisibilização das situações de violências envolvidas. Este processo, se tem historicamente uma comprovada eficácia técnica e simbólica, é concebido como medicalização, reduzindo a patologias problemas que, além de médico-sanitários, são sociais. Desvelar a violência no interior dos serviços de saúde é, portanto, fundamental para que a situação possa ser compreendida em seu todo médico e social e práticas assistenciais adequadase intersetoriais, com a qualidade de um cuidado integral, possam ser oferecidas. Este processo resultaria no entrosamento da saúde com os direitos humanos (e o das mulheres), lidando-se com sua violação em busca da recuperação desses direitos no restabelecimento da ética nas rel ações interpessoais, além do tratamento integrado dos agravos à saúde constatados e recorrentes. Esta perspectiva recoloca, portanto, os objetivos e o papel dos serviços de saúde, reorientando-os para um cuidado integral na assistência cotidiana e, sobretudo, fazendo-os somar com outras atuações sociais em movimentos ético-políticos contraa violência e a favor de seu controle e prevenção.

Recuperemos as práticas, serviços einstituições que vêm sendo constituídos para lidar com problema nos últimos anos no Brasil, focalizando especialmente o papel da saúde por meio de uma rápida recuperação da implantação de serviços voltados à violência contra a mulher no país. $\mathrm{N}$ essa abordagem, aponta-se para a, ainda hoje, gran- de questão da invisi bilidadeda violência, mostrando distintas formas possíveis ou em uso de tornála mais visível, a depender desua definição ou compreensão como problema, gerando formas diversas de lidar com as dificuldades de revelação. Também seaborda a importância do trabalho em equipe e das redes intersetoriais, discutindo especialmente a perspectiva da atenção primária na proposta de um cuidar integral ${ }^{11}$.

\section{Estratégias iniciais de enfrentamento da violência de gênero na saúde: o cuidado aos casos de violência sexual}

A primeira aproximação do campo da saúde com a violência contra a mulher no Brasil foi a implantação, entre $1989^{12} \mathrm{e} 1990^{13}$, deum primeiro serviço de saúde que realizava o aborto nas situações previstas na Constituição brasileira desde os anos quarenta (estupro e risco de vida para a mãe). Assim, o problema incorpora-se à saúde e dá visibilidade nesse campo por sua delimitação de violência do tipo sexual e cometida por estranhos. De outro lado, a medida está mais voltada para a possibilidade do aborto do que para o enfrentamento daviolência.

Posteriormente, muitos desses serviços foram criados pelo Brasil e, em 2002, havia 245 serviços de saúde capacitados a atender mulheres vítimas de violência sexual e 39 hospitais oferecen do a realização do aborto legal ${ }^{13}$.

Apoiando esses serviços, a N orma Técnica sobre Prevenção e Tratamento dos Agravos Resultantes da Violência Sexual contra Mulheres e Adolescentes, publicada em 1999 e com diversas reedições posteriores ${ }^{14}$, criou um protocolo de atenção à violência sexual para mulheres em idadereprodutiva, detalhando a profilaxia de DST, medicação antiretroviral, gravidez indesejada e o apoio psicossocial a ser prestado a estas mulheres. Apesar de essa norma ser escrita para mulheres e adolescentes, a edição de 2005 traz as doses de medicação também para crianças, ainda que elas não sejam alvo de outras ações específicas no restante da proposta.

Dos serviços existentes, nem todos conseguiram uma implantação efetiva. Alguns realizam quase nenhum ou nenhum aborto ${ }^{13,15}$, outros não são conhecidos dentro do próprio hospital em que atuariam e tampouco são reconhecidos pelos serviços componentes da rede que poderia encaminhar casos, seja na saúde ou intersetorial ${ }^{15}$.

Além disto, a grande maioria esta concentrada nas grandes capitais, são poucos para a demanda potencial e atendem, na maioria dos casos, a vio- 
lência sexual prevista, isto é, a cometida, no caso das mulheres adultas, por estranhos. No caso das crianças, os agressores serão mais os conhecidos do que os estranhos, porque os casos são majoritariamente familiares ${ }^{16}$.

Portanto, estes serviços, extremamente necessários, não recobrem, ainda, toda a demanda ge rada pela própria violência sexual, por um lado, e pouco podem fazer pela violência não sexual, como as físicas ou psicológicas, contra a mulher, por outro.

As taxas obtidas em estudos populacionais demonstram que a maioria das violências, mesmo a sexual, contra mulheres adultas é perpetrada por parceiros ${ }^{17}$ e estes episódios acabam praticamente ausentes destes serviços. 0 apoio fornecido pela norma técnica, por sua vez, tampouco serve a essas violências, já que mulheres envolvidas em violências repetitivas nas quais o agressor e a vítima moram juntos e/ou são familiares não podem se beneficiar do protocolo prescrito (medicação profilática), pela cronicidade da situação e a recorrência do abuso. A proposta tecnológica, pensada em função da garantia do aborto legal previsto em lei e dirigida a mulheres em idade reprodutiva, também se adéqua pouco ao cuidado da violência se xual cometida contra homens e crianças, já que as equipes geralmente não prevêem profissionais e ações específicos, além de, no caso dos homens, existir dificuldade adicional em atendê-los, por não serem considerados como potenciais vítimas de agressão, dadas as concepções de gênero aderidas a maior parte da equipe profissional ${ }^{18}$.

\section{A potencialidade da atenção primária no} atendimento à violência por parceiro íntimo

Ainda que a violência contra as mulheres tenha como principais agressores os parceiros íntimos, o reconhecimento da violência psicológica, física e sexual cometida por parceiro íntimo em serviços de atenção primária à saúde ainda é muito pequena. Em estudo realizado na região metropolitana de São Paulo, em dezenove serviços de saúde de atenção primária, a violência física e/ou sexual por parceiro íntimo na vida foi de 45,3\% (IC 95\%: $43,5 ; 47,1)$ e por outros que não o parceiro foi de $25,7 \%$ (IC 95\%: 25,0;26,5). Observou-se registro de episódios de violência, entretanto, em apenas $3,8 \%$ dos prontuários ${ }^{19}$.

Cabelembrar, portanto, que os serviços deatenção primária já assistem, em grande medida, casos de violência doméstica cometida contra mulheres. Ainda que não reconhecidos como tal, estes casos estão presentes no cotidiano dos serviços e geram a demanda reiterada e com baixa resolutividadejá discutida.

Ainda quando enunciada a violência, ela não é reconhecida para o trabalho, já que não existem ações previstas para isto. Ou seja, para a violência doméstica, não há o equivalente à norma técnica para a violência sexual, que orienta as ações a serem realizadas. Portanto, ainda que a mulher diga que foi agredida física ou sexualmente, o profissional poderá até comentar sua opinião a respeito, mas o fará, como mostra estudo a respeito ${ }^{7}$, como uma interven ção decaráter pessoal enão como procedimento técnico. Na maior parte dos casos assistidos nos serviços de saúde, um conjunto de profissionais trata o conjunto das demandas de uma mesma mulher, com pouco conhecimento de cada um sobre o trabalho dos outros e muito menos ainda sobre a situação de violência que pode estar envolvida em várias das queixas e sintomas relatados.

Queremos tratar das potencialidades da atenção primária para intervenção sobre o problema, deuma perspectiva integral. Integral porquesetrata de acolher a violência como problema em toda a sua complexidade, pensando na promoção da não violência, preven ção e cuidado aos casos, tanto da perspectiva do tratamento de suas consequências como da especificidade do setor saúde na abordagem do problema violência em si, que sendo um tema complexo, interdisciplinar, leva à necessária multiprofissionalidadeeintersetorialidade da atenção, como se verá. Integral também porque se trata de uma decisão assistencial em que a mulher usuária deve ser considerada como centro da tomada das decisões para a atenção e participar dessas decisões referentes ao seu cuidado.

A atenção primária mereceum destaquequando se trata de ações referentes à violência contra a mulher por diversas razões. Em primeiro lugar, este nível de atenção tem grande ênfase nas ações de promoção e prevenção de saúde. Além disto, tem um aumento de cobertura e incremento recente, com valorização da ida ao domicílio através da crescente implantação da Estratégia de Saúde da Família. Este nível de atenção enseja um acesso frequente, constante e legitimado às mulheres ao longo de toda a sua vida, uma relação mais próxima com a comunidade e é dirigida a problemas comuns de saúde muito associados com violência doméstica e sexual contra a mulher.

Em relação ao enfoque na promoção da saúde e prevenção, esta perspectiva acaba sendo a que possui menor acúmulo no trabalho com a questão. Se tomarmos a violência doméstica contra as mulheres como relacionada à desigualdade e aos 
conflitos derivados detransformações recentes nas relações de gênero, e também como rompimento da comunicação interpessoal, todas as ações dirigidas a uma maior equidade de gênero eà possibilidade de comunicação interpessoal não instrumental podem contribuir para sua diminuição.

No sentido da prevenção dos casos e promoção da não violência, diversas ações podem ser sugeridas, desde uma perspectiva populacional, e que não passam necessariamente pela ação dos serviços de saúde. São elas: as campanhas em meios de comunicação de massa; a educação para a igual dade de gênero; o controle de armas na sociedade; o controle da violência urbana; o controle da publicidade e do abuso de álcool; a igualdade de salários entre homens e mulheres; a igualdade na participação política.

Estas ações costumam ter pouca articulação com o trabalho assistencial e praticamente nenhuma avaliação neste sentido. Alguns poucos trabaIhos internacionais demonstram menores taxas de violência de gênero contra mulheres em locaiscom menor desigualdade de gênero ${ }^{20}$, mas este ainda é um tema em que há muito por explorar.

A prevenção, entretanto, também passa por ações que podem ser realizadas pelos serviços de saúde. Em primeiro lugar, o combate à violência institucional e o estímulo à integralidade da atenção são promotores da boa comunicação e relações interpessoais no serviço, denotando de modo exemplar a prática da não violência e, por contraste, apontando sua recusa e a não reprodução desta no interior dos serviços. Assim, o propósito de tornar visível a violência como questão, atuando contra sua banalização, é uma prática que começa "em casa", no próprio serviço de saúde. 0 trabalho orientado pelos princípios do PAISM (Programa de Atenção Integral à Saúde da Mulher), com a promoção dos direitos reprodutivos e sexuais e 0 trabalho com conflitos de gênero da perspectiva de fortalecimento das mulheres e emanci pação de todos os usuários e trabalhadores, é fundamental neste sentido.

Além disto, é necessário que se compreenda o papel de todos os profissionais do serviço, em especial dos Agentes Comunitários de Saúde (ACS), na dimensão preventiva do serviço. Setodos os profissionais podem ser divulgadores de direitos humanos e da rede intersetorial que presta apoio à violência, e também provêtrabalho, moradia, creche, escola, que são todos elementos fundamentais para a emancipação e uma vida livre de violência, os ACS encontram-sena espeć́fica situação de acesso e relação diferenciada frente às questões do domicílio e da vida comunitária das/dos usuárias/ usuários do serviço. Ao contrário do quevem acontecendo em alguns programas e unidades, os ACS não deveriam ter papel central na detecção e orientação e assistência dos casos, já que a sua proximidade com a comunidade os coloca em posição de maior risco de quebra de sigilo e vulnerabilidade à própria violência. M as no que diz respeito a serem promotores da não violência por meio da divulgação e informação sobre direitos e serviços existentes na comunidade e fora dela, sim, seriam agentes privilegiados.

Devemosconsiderar, ainda, queo ambientemais acolhedor ao tema e sem temor de tratá-lo publicamente, tal como a colocação de cartazes e fol hetos nas unidades, é uma prática que pode facilitar a revelação e a emergência de casos, lembrando-se que o cuidado mesmo aos casos já instalados tem uma forte dimensão preventiva: testemunhar violência entre os pais, na infância, ou sofrer violência quando criança é importante fator de risco, tanto para meninos como para meninas, para o envolvimento em situações de violência na vida adulta ${ }^{21}$. Portanto, o cuidado aos casos pode proteger as crianças e prevenir a transmissão intergeracional da violência, ao mesmo tempo em que pode prevenir as constantes reiterações dos episódios para a própria mulher em situação de violência. 0 cuidado aos homens, na mesma direção, pode trazer uma perspectiva crítica e prevenir futuros novos episódios de violência com as mesmas ou outras mulheres com quem se relacionem, sejam elas parceiras, familiares ou colegas e conhecidas.

Além desses aspectos já tratados, o que mais poderia a atenção primária à saúde realizar? $\mathrm{H}$ ave ria uma atuação específica de seus profissionais? Q uais podem ser estas ações específicas dos profissionais de serviços de atenção primária em relação ao problema da violência doméstica contra as mulheres?

Posto desse modo, a tomada da violência como objeto da intervenção das ações em saúde corresponde, para o trabalho de seus profissionais, conceitualmente, à constituição da violência como objeto desse trabalho, exigindo a definição de uma dada abordagem do objeto, vale dizer, uma dada aproximação da violência para a sua transformação após a intervenção técnica ou o agir profissional. E isto também exige definir em mesmo sentido os instrumentos materiais e os saberes a serem mobilizados no trabalho cotidiano dos profissionais na atenção primária. Portanto, devem ser redefinidos nesta atenção os arranjos das ações profissionais e de fluxos, atividades e protocolos previstos para o problema, bem como as formas de interação na equipedetrabalho ${ }^{22,23}$. Propomosaqui 
que a finalidade última do trabalho com violência contra a mulher seja o fortalecimento das mulhe res e a emancipação de todos os envolvidos (população e profissionais), e não apenas o alívio da dor e o tratamento dos sintomas e agravos consequentes à violência, o que reorientaria os objetivos mais tradicionais de base biomédica do trabalho profissional em saúde. Para isto, é necessária uma forma de agir com uma importante dimensão interativa, baseada na escuta, na orientação, no acoIhimento, com ênfase na comunicação com a muIher usuária e entre os profissionais, na direção de projetos assistenciais negociados e construídos em conjunto para cada caso, tendo como referência a garantia de direitos e a emancipação. M as como transformar os valores, especialmente relativos às conformações sociais de gênero aos quais muitos aderem, em ação culturalmente crítica no cotidiano dos serviços? Como realizar esta proposta, que é ética e política, além de assistencial, na forma de uma técnica compreendida como parte do escopo profissional no interior dos serviços?

Expõe-se, a seguir, uma possibilidade nessa direção: uma "técnica de conversa", cuja base é a de tecção, escuta e orientação qualificadas para o trabalho com violência contra as mulheres na atenção primária à saúde. Tal possibilidade, resultado das reflexões teórico-conceituais, dos dados produzidos nas pesquisas e da experiência conduzida epre liminarmenteavaliada em uma unidade de atenção primária, aponta como essa técnica atuaria como elemento orientador da conversa que pode ocorrer cotidianamente nos serviços de saúde, nos encontros entre profissionais e usuários. Se pensarmos os serviços de atenção básica como uma rede de conversações ${ }^{24}, 0$ assunto da violência contra a mulher necessita de certas condições para ser conversado da perspectiva do fortalecimento e emancipação. Trata-se, pois, não de uma conversa pessoal e de aconsel hamentos que se fariam pela amizade ou simpatia pessoal ao caso. Em analogia à anamnese clínica, esta é uma conversa específica, especialmente formulada e real izada para produzir orientações pertinentes ao caso e encontrar formas de resolução da situação em que se en contra a muIher. Por isto é uma técnica, isto é, uma aproximação transformadora de seu objeto de intervenção na direção de determinada finalidade que esta ação pretende alcançar, como dito, a de fortalecimento emancipatório da mulher e crítica à banalização da violência e desigualdades de gênero com valorização dos direitos humanos e sociais.
Um modelo de atenção à violência implantado: 0 atendimento aConflitosFamiliares Difíceis (CONFAD)

Implantamos, em um distrito da região oeste de São Paulo, uma atenção específica para casos de violência contra a mulher no Centro de Saúde Escola Samuel B. Pessoa (do Butantã), articulado ao atendimento à violência sexual que ocorreno $\mathrm{H}$ ospital Mario Degni, secundário, e concomitante à implantação e treinamento conjuntos para todos os serviços de saúde do distrito. Chamamos esta proposta de atendimento voltada aos conflitos familiares difíceis de CONFAD, evitando o termo violência, que não é utilizado por uma parte significativa das mulheres para definir as situações domésticas, que são a esmagadora maioria da demanda atendida ${ }^{25}$. Esta proposta de trabal ho, que vem sendo multiplicada em outras unidades de saúde em São Paulo, no Distrito de Saúde do Butantã, em outras Unidades e fora dele, como no Centro de Saúde Escola Alexandre Vranjac (da Barra Funda), necessita certas condições institucionais prévias que são, elas mesmas, o início do trabalho contra a violência e a favor de uma interação de maior qualidade entre profissionais e população. São elas: o compromisso eenvolvimento de todos os profissionais da instituição e inequívoco apoio da gerência; a crítica à violência institucional eestabelecimento derelações deescuta e respeito no interior da unidade de modo geral; 0 trabalho comprometido com o ideal da integralidade, defesa dos direitos reprodutivos e sexuais e crítica à desigual dade de gênero, com implantação dos princípios do PAISM.

Para tanto, em primeiro lugar, todos os profissionais e trabalhadores do serviço foram sensibilizados para os temas da violência contra a muIher, dos direitos humanos e das mulheres e das relações degênero. 0 processo incluiu: os profissionais da recepção e trabalhadores da limpeza e administração; pessoal e técnicos da farmácia; profissionais etécnicos do atendimento odontológico e da assistência social; médicos, enfermeiras e pessoal auxiliar de atuação em outros setores de atendimentos que não o das mulheres, como a pediatria, vacinação, saúde mental e saúde do adulto de modo geral (no caso incluindo os que atendem adolescentes e idosos), além dos ACS do serviço. Esta primeira sensibilização é fundamental e deve ser mantida continuadamente no tempo, com encontros regulares a cada seis meses ou anualmente, para que 0 trabalho tenha consistência e seja apropriado por todos. Um cuidado especial precisa ser tomado porque não se deve esquecer que a 
grande maioria dos trabalhadores de saúde são mulheres. A enfermagem, especialmente, é uma categoria que refere altas taxas de violência doméstica ${ }^{26}$. Os profissionais de saúde, portanto, necessitam abordagem especial, levando em consideração que muitas também passam por situações semel hantes e devem ser acolhidas pelo serviço desde o treinamento, sem exposição. Viver ou ter vivido violência não impossibilita o trabalho com as pacientes, mas deveser considerado no treinamento e supervisão dos profissionais. A possibilidade de trabalho melhor ou pior com o tema depende da elaboração que a profissional fizer sobre ele e suas vivências e também do seu desejo de trabalhar com o assunto ou não.

Este treinamento também é fundamental porque a detecção é o primeiro obstáculo ao trabalho efetivo. A detecção depende, em grande parte, da certeza dos profissionais de que haverá desdobramentos assistenciais de boa qualidade, ainda que não se esgotem na assistência prestada por cada um deles isoladamente. Assim, a proposta do CONFAD é de haver um espaço específico, com profissionais com treinamento mais detalhado e tempo maior para trabalhar com maior profundidade o problema da violência, mas todos os profissionais devem estar envolvidos e apoiar a detecção dos casos. Para isto, énecessário operacionalizar uma definição de violência tal que permita delimitar o que seja um caso. A definição adotada, nesta proposta, baseia-seem dois parâmetros principais, derivados diretamente das pesquisas sobre a violência de gênero contra as mulheres: a ocorrência de atos violentos, caracterizando uma vivência da mulher desituações de violência, quesão atos bem discriminados e concebidos como comportamentos concretos e particulares de exercício da desigualdade de gênero por parte do agressor; e a presença de demandas e queixas repetidas pelas mulheres no serviço que são estatisticamente associadas, conforme toda a literatura, à violência, funcionando como indicadores indiretos desta.

Discriminam-se, a seguir, na forma de um rol de ocorrências, tanto os comportamentos quanto as demandas clínicas das usuárias, com o propósito de indicar a importância, para uma ação do tipo técnico, de se delimitar o mais precisamente possível os elementos componentes do diagnóstico em questão: o caso de violência. Assim, situação de violência seriam:

. ataques a entes queridos, objetos pessoais ou animais de estimação;

- restrição de liberdades individuais (impedimento de trabalhar fora; estudar; ou sair de casa, mesmo para visitas a familiares);
. práticas que resultam em restrições de liberdades, como não disponibilizar dinheiro para a lida diária; ameaças de agressão ou brigas verbais associadas às saídas;

. humilhação; maus tratos, desqualificações públicas ou privadas; xingamentos e ofensas por conhecidos e/ou familiares;

. discussões e brigas verbais frequentes;

. ameaças de agressão; ameaças com armas ou instrumentos de agressão física;

- relações sexuais forçadas;

- submissão a práticas sexuais indesejadas;

. agressão física de qualquer espécie (incluindo atos como bater, empurrar, puxar cabelos, beliscar, estapear, espancar, agredir com objetos, queimar, tentar estrangular, ameaçar o uso de, ou efetivamente usar, armas de qualquer tipo), seja a agressão sofrida ou cometida, contra adultos ou crianças.

Quanto às repercussões na saúde, consideramos os sintomas e sinais de natureza física emental, tais como:

- Transtornos crônicos, vagos (inespecíficos dentro da nosografia médica) e repetitivos;

. Entrada tardia no prénatal;

- Companheiro demasiadamente atento, controlador e que reage se for separado da mulher;

. Infecção urinária de repetição (sem causa secundária encontrada);

. Dor pélvica crônica;

. Síndrome do intestino irritável;

. Transtornos na sexualidade;

. Complicações em gestações anteriores, abortos de repetição;

- Depressão;

. Ansiedade;

- Transtorno do estresse pós-traumático;

. História de tentativa de suicídio ou ideação suicida;

. Lesões físicas que não se explicam como acidentes.

N os casos em que alguma destas condições é identificada, os profissionais são treinados a investigar violência. A detecção émuito importante, já que tanto mulheres como profissionais podem banalizar a ocorrência, desconsiderá-la como violência ou perceber o problema da violência como exterior à saúde. 0 primeiro obstáculo apontado por profissionais é a detecção dos casos, já que há uma impressão de que as mulheres não gostariam ou ficariam constrangidas de falar sobre a violência sofrida e que a esconderiam dos profissionais. No entanto, na avaliação realizada, ainda que bastante preliminar, desta nossa experiência de trabaIho, fica claro tanto o benefício da revelação para 
as mulheres, que manifestam querer e sentir-se melhor depois de feita essa revelação, como o fato de que quanto mais o profissional é treinado na questão mais fácil fica realizar a detecção dos casos. As mulheres precisam e querem falar sobre a violência de uma forma privada, sigilosa enão julgadora do acontecido por parte do profissional. $\mathrm{N}$ ão se trata aqui de um interrogatório ou de uma confissão. Basta escutar e estar atenta ou atento, dando crédito ao relato e produzindo uma narrativa que Ihe permita identificar os elementos da história com potenciais de transformar a situação deviolência.

As mulheres falarão daquilo quequeiram elhes interesse. Para isto, émuito importantequea reve lação da violência não se transforme em encaminhamentos automáticos, pressão por determinadas ações (ir à DDM ou separar do agressor, por exemplo). Perceber quea visibilidade daviolênciaé importante para o cuidado em saúdeécentral, mas não se trata aqui de um interrogatório policial - a mulher pode, por diversas razões, temer a revelação em um determinado momento, e isto deve ser respeitado. Tampouco se trata de confissão, sendo mais importante que ela perceba que o serviço se interessa pelo problema de uma forma não julgadora e percebe as suas repercussões para a saúde, tendo recursos para apoiar os casos. É importante que a mulher possa contar aquilo que lhe parece significativo, e que, nos diversos contatos com o serviço, ela vá percebendo que o sigilo ea segurança serão levados em conta, assim como suas opiniões, valores evontades. Perguntas diretas são importantes, mas a escuta interessada ainda é o meIhor instrumento de detecção.

Pode acontecer nos serviços que, ao se ouvir a revelação da violência, as demais queixas sejam desconsideradas e tratadas como menos importantes. Este comportamento parte do princípio de que as queixas não se constituiriam em sofrimentos efetivos, mas por estarem associadas a um problema da esfera social, não sendo sinais de doenças "verdadeiras", as que correspondem à nosografia médica. Ou seja, os sintomas revelados não corresponderiam a lesões a serem encontradas no corpo conforme definido pela biomedicina, mas seriam percebidos como, grosso modo, falsos sinais, "invenções da cabeça" da mulher. As mulheres que sofrem violência apresentam, conforme a literatura, mais sofrimentos e demandas aos serviços, o que não significa que não mereçam investigação clínica, muito pelo contrário. Estas mulheres têm maior risco efetivo de patologias clínicase mentais, e devem ser investigadas com cuidado e cautela, ao mesmo tempo em que são aconselha- das e acolhidas em suas situações de violência, raiz de uma parte dos problemas. A não conjugação de esforços nesse sentido, agregando-se a atenção à violênciaàs investigações clínicas, podelevar o profissional a cometer erros diagnósticos graves, também do ponto de vista técnico-científico. As queixas clínicas precisam ser levadas em conta, assim como a história da violência, para que se possa compreender os casos em seu todo, enquanto um cuidado integral a ser dispensado. Tal conjugação de esforços não necessariamente constitui trabaIho de um só profissional, mas de uma equipe de profissionais de diferentes áreas de atuação.

Outra questão importante apontada pela literatura é a al egação dos profissionais de não saberem como perguntar sobre a violência. Diversas formas de perguntar são possíveis, como demonstra o rol abaixo, e cada profissional deve encontrar a mais apropriada para cada mulher e para si própria (o) na relação estabelecida com o caso. Perguntas diretas podem ser importantes, desde que não estigmatizem ou julguem as mulheres, para não se romper o interesse demonstrado pelo serviço relativamente ao problema.

Pode-se perguntar indiretamente:

Sabe-se que mulheres que apresentam problemas de saúde ou queixas como os seus muitas vezes têm problemas de outra ordem em casa. Por isto, temos abordado este assunto no serviço.

Está tudo bem em sua casa, com seu companheiro? ou

Você está com problemas no relacionamento familiar? ou

Você se sente humilhada ou agredida? ou

Você acha que os problemas em casa estão afetando sua saúde? ou

Você e seu marido (ou filho, ou pai, ou familiar) brigam muito? ou

Quando vocês discutem, el e fica agressivo?

Pode-se também perguntar diretamente:

Como você deve saber, hoje em dia não é raro escutarmos sobre pessoas que foram agredidas física, psicológica ou sexualmente ao longo de suas vidas, esabemos que isto pode afetar a saúde mesmo anos mais tarde. Isto aconteceu alguma vez com você? ou

Já vi problemas como o seu em pessoas que são fisicamenteagredidas. Isto aconteceu com você?? ou

Alguém Ihe bate? ou

Você já foi forçada a ter relações com alguém?

I dentificado o problema, é oferecido à mulher um espaço apropriado para a discussão mais aprofundada do problema e de suas possibilidades de enfrentamento, que é a atividade CON FAD. 
Esta atividade dura cerca de uma hora e pode ser reagendada por até mais três vezes, contabilizando a princípio um máximo de quatro sessões. $\mathrm{Na}$ avaliação feita, encontrou-se que a média de duração está entre cinquenta a sessenta minutos e a grande maioria das mulheres têm demandado no máximo duas sessões. Como já dito, nela ope ra-se uma técnica específica de conversa que produz uma orientação, em conjunto com a mulher, mapeando o problema e alternativas de solução, isto é, formas de lidar com a situação de violência que não configura uma única forma sempre para os casos ou o mesmo mapa de alternativas para todas, como seria o caso de um protocolo tradicional. Pode ser conduzida por qualquer profissional de saúde treinado, seja médica, enfermeira, assistente social ou psicóloga, mas a preferência éde que a condução seja feita por uma profissional mulher, buscando a identidade de gênero e uma maior solidariedade e cumplicidade.

Seus princípios e conteúdos são todos interligados entresi. Um primeiro princípio diz respeito ao tempo disponibilizado para a atividade, pois embora se tenha previsto cerca de uma hora, o tempo deverá ser aquelenecessário para que, uma vez feito o vínculo de confiança entre o profissional ea muIher, e esta se sinta bem em seu rel ato, a revelação da mulher defineo tempo necessário. Elejáémaior do que aquele habitualmente reservado às consultas médicas e deenfermagem, ealgumas mulheres precisam um pouco menos de tempo e outras, de um pouco mais. Detoda a forma, saber queeste tempo será disponibilizado dá mais condições para os profissionaisqueidentificam os casos eos encaminham para o CONFAD de que possam fazêlo de forma mais preliminar, simplificando o encaminhamento, pois se tem a garantia que haverá aprofundamento posterior dos casos. Outro princípio importanteé o da privacidade: este princípio geral do cuidado em saúde toma aqui uma importância ainda maior. 0 assunto da violência só pode emergir em encontros em ambientes que garantam a privacidade. Isto significa, no cotidiano dos serviços, salas fechadas, encontros privativos e que não possam ser escutados por outros, sejam profissionais, usuários ou familiares. Um terceiro princípio seráa questão do sigilo, poiséfundamental, inclusivepara a segurança dos envolvidos. Estende-se ao uso e manuseio dos prontuários e deve ser mantido pelo serviço, ainda que as informações possam e devam circular entre a equipe. A disposição dos móveis da sala, a fim de facilitar o encontro e o contato diferenciado de uma consulta médica, como por exemplo cadeiras dispostas para uma conversa, configura importanteimagem imediata de um ambiente acolhedor. Este ambiente acolhedor caracteriza um quarto princípio.

Outro princípio éo desenvolvimento de vínculos de confiança, o que requer atitude de respeito para com a mulher, ao sedemonstrar interesse pela sua situação, e um procedimento de escuta sem julgamento da história narrada. A confiança está associada ao sigilo eà privacidade, que promovem o sentimento desegurança na mulher que relata de que o profissional está interessado em apoiá-la e em construir o melhor para ela, enão vai traí-la ou desapontá-la em seus desejos expressos enas combinações firmadas. A sinceridade é fundamental aqui de parte a parte. A postura de respeito, por sua vez, a valores e opiniões que podem ser muito diversos dos do profissional é fundamental, buscando a comunicação interessada na compreensão do outro como sujeito livre e autônomo. Talvez a postura mais difícil seja essa resultante do respeito à usuária que é a escuta sem julgamento, escuta que busca a compreensão mútua sem procurar culpados e inocentes. Assim, o profissional não deve julgar, nem moralmente a mulher, por suas dúvidas, comportamentos específicos ou condutas e valores queadote, nem legalmenteo agressor, indicando à usuária uma atitude de "punição" ao agressor, embora adote de modo claro a não violência como sua conduta ética e social, e demonstre seu agir no caso como interessado em resolver a violência na direção das relações dialógicas e interativas. Nisto mostra sua ação como diversa da ação da justiça (que pode e deve ser acionada em muitos casos) ou de líderes religiosos na questão moral, tratando de compreender a lógica das ações e os valores dos envolvidos. Não significa que o profissional não tenha seu código de ética eseu agir moral, mas, para diferenciar essa conversa de uma atividade de caráter pessoal e dotá-la de sentido profissional, seu desempenho não inclui recomendações de ordem moral, religiosa ou punitiva. 0 reconhecimento dos próprios preconceitos é necessário para que concepções rígidas acerca, por exemplo, de relações familiares, fidelidade, relação com álcool e drogas ou outras não obstaculizem o trabalho de compreensão da mulher eo manejo da conversa no sentido da afirmação dos direitos humanos e de uma ética da não violência nas relações interpessoais. Esta “vigilância cultural" que o profissional deverealizar acerca de seu próprio agir inclui a atitude de evitar a vitimização da mulher. É fundamental que não transformemos o problema em algo naturalizado, isto é, as mulheres como vítimas por uma característica que Ihes seria essencial, parte de suas qualidades de ser mulher. Assim, deve-se criticar a 
visão mais comum, e muitas vezes da própria mulher em atendimento, de que seriam as mulheres vítimas cristalizadas de uma violência natural dos homens. Lembremos que a situação é produto de relações e se as relações de gênero expressamse por relações de poder desiguais para as mulheres, há semprepossibilidades de resistência eluta, e a escuta e a informação nos serviços podem colaborar neste sentido. A vitimização das mulheres, que pode ser potencializada pela identificação de gênero com profissionais mulheres, é contraprodutiva ao trabalho e acaba por fortalecer a cristalização em posições predefinidas. As mulheres transgressoras, que traem seus maridos, revidam ou iniciam a violência, não encontram, neste enquadre, espaço de fala, porque tenderiam a não ser reconhecidas como vítimas. Antes passariam a ser tomadas como "provocadoras" da violência. O utro aspecto dessa importante "vigilância cultural" do trabalho do profissional é seu lidar com as suas próprias emoções, pois os relatos escutados são fortemente mobilizadores de diversas delas, sendo as mais comuns a raiva, o medo e a impotência. A consciência crítica destes sentimentos deve ser buscada para o bom atendimento e também para o crescimento eaperfeiçoamento do profissional, prevenindo sua interferência moral ou puramente emocional reativa no trabal ho assistencial. Disto se discorrerá mais adiante ao ser tratada a questão da supervisão desse atendimento.

Além dos princípios da conversa, arrolam-se a seguir os conteúdos que devem ser abordados, o que é apresentado na forma de itens pelo sentido técnico que se quer reforçar dessa conversa. São eles:

. Estímulo à narrativa detal hada e reflexão sobre as origens da violência (gênero e outros eixos de desigualdade de poder) - durante o relato, aspectos relativos a conflitos de poder baseados nas relações de gênero (dupla moral sexual, trabalho doméstico, divisão e destino do dinheiro, tempo para o lazer, etc.) podem ser apontados e discutidos, relacionando-os às origens da violência;

- I dentificação de riscos - homicídio, suicídio, violência contra crianças: na presença de riscos, estes devem ser apontados e medidas de segurança podem ser tomadas. Quando violência contra crianças éidentificada, a obrigatoriedade da notificação esuas consequências devem ser discutidas, para que as medidas a serem tomadas sejam no sentido da proteção das crianças, no melhor benefício e com a concordância de todos. A mulher em risco demorte deve ser encaminhada a abrigose/ou atendimento especializado em casos deideação ou tentativas de suicídio;
- Identificação da rede desuportesocial já existente - extremamente importante para evitar a vitimização, a rede de suporte existente deve ser reconhecida e valorizada - seja ela trabalho, educação, amizades, alguém da família ou outro apoio comunitário existente;

- Identificação de pontos positivos nos relatos de vida - durante 0 atendimento, devem ser buscadas na história da mulher as possibilidades de relações maisigualitárias, tentando-se resgatar elementos em sua experiência de vida que se configurem como apoios ao exercício mais pleno de sua subjetividade, constituindo uma reflexão no sentido emancipatório da mulher. É importante reforçar que não existem respostas "certas" de antemão, mas sim uma possibilidade de maior reflexão crítica sobre as situações;

- I dentificação das conexões violência-saúde a forma como a mulher entende as relações entre suas queixas e a situação de violência e os caminhos para a resolução de ambas são fundamentais. 0 reconhecimento das conexões existentes e suas formas de superação é o motivo final do trabalho e justifica sua tomada pela saúde. Via de regra, esta conexão ébastante clara para as mulheres usuárias, por vezes de forma ainda mais contundente do que para os próprios profissionais, desde que estereconhecimento não leve à desqualificação da queixas clínicas, como considerado;

- Valorização do relato com seu registro - o registro deve ser detalhado, para o acompanhamento do caso por toda a equipe e para usos futuros que possam ser necessários, inclusive para uso como evidência em processos judiciais;

. Compartilhamento de informações sobre a redeintersetorial de serviços - escutada a história, a rede de serviços adequada à situação deve ser exposta pelo profissional para que a mulher a conheça e possa decidir quais apoios serão mais importantes no momento para ela. Esta rede deve incluir, a depender dos casos, serviços policiais, de assistência jurídica, psicossocial, abrigos e recursos comunitários menos específicos, como atividade de cultura e lazer, educação, creche, trabalho, moradia, etc.

. Projetos novos de vida e decisão compartiIhada sobre caminhos possíveis e referência aos serviços que ela escolher - apresentada a rede, a mulher decidirá, em conjunto com o profissional quea atende, seus próximos passos na rota deatenção. A idéia de rota supõe que a transformação das situações violentas é composta de caminhos possíveis, decisões e ações que impulsionam ou obstaculizam o caminho. Esta rota, que é considerada "crítica"27, podeser impulsionada por estetra- 
balho, na direção definida pela mulher a partir das informações e reflexões realizadas pelos profissionais do serviço e especialmente pelo trabalho no CONFAD;

M onitoramento do caminho (seguimento ou retorno sempre que ela o desejar) - a mulher poderá voltar sempre que desejar, com novas demandas e/ou discutindo os resultados dos caminhos tomados;

. É também fundamental o apoio da gerência do serviço e em nível central. Ações de notificação para instituições externas aos serviços (a Vara de Crianças e Adolescentes, o Conselho Tutelar ou os Fóruns) devem ser realizadas pela gerência local, complementando o trabalho dos profissionais diretamente no caso e dando respaldo institucional, e a notificação para a Vigilância Epidemiológica também necessita da estrutura da unidade e do incentivo da coordenação em nível central. Além disto, é necessária a garantia de condições materiais e tempo para trabalho adequado aos casos e sua supervisão.

Por fim, há que se considerar mais dois outros componentes essenciais de gestão da proposta, as avaliações da atividade e as supervisões dos profissionais.

Avaliar éuma prática fundamental, o que neste caso é bastante particular e complexo. Uma das dificuldades, por exemplo, está em delimitar o objetivo final a ser al cançado. Como o trabal ho tem como objetivo principal o encontro ea delimitação compartilhada de caminhos possíveis para cada muIher, não há um objetivo predefinido além da compreensão mútua e encontro de soluções possíveis para cada momento. A avaliação, seguindo este caminho, necessita verificar o impacto da atividade no trabalho dos profissionais enos projetos devida das mulheres atendidas. Outra dificuldade para a avaliação é estimar o tempo necessário para as mudanças pretendidas, já que são situações crônicas que muitas vezes demoram longos períodos para que ocorram mudanças significativas.

Em nossa avaliação preliminar ${ }^{28}$, verificamos, de um lado, o número crescente ao longo dosanos de encaminhamentos (de 41 casos atendidos, em 2000, a 153, em 2003), sugerindo progressiva adesão dos profissionais à proposta. Também verificamos, utilizando entrevistas semi-estruturadas, que as usuárias valorizaram em maior grau a escuta acolhedora do que as informações fornecidas acerca de serviços disponíveis ou legislação, por exemplo. Verificamos também que a falta à atividade, posto ser agendada, foi semelhante às obtidas para as consultas médicas, em torno de $25 \%$, e que mais de $80 \%$ dos casos atendidos foram vio- lência provocada por parceiros íntimos, repetindo um padrão recorrente nas Delegacias da Mulher. Um aspecto, contudo, muito estimulador, foi o reconhecimento, por meio do estudo dos prontuários dessas mulheres atendidas, de que parte significativa delas alterou o uso da Unidade após seus atendimentos no CONFAD, diminuindo suas demandas de pronto-atendimento e voltando-se mais às sessões do próprio CONFAD ou outras modalidades assistenciais programadas.

A supervisão, por sua vez, garante a qualidade da atividade e ao mesmo tempo possibilita atuar sobre os desgastes e sofrimentos do profissional. A supervisão pode ser feita por profissionais especializados, de formações diversas, mas também entre pares, do mesmo serviço. 0 fundamental é que haja diálogo e reflexão sobre os casos atendidos, pois, apesar de princípios comuns, cada caso é bastante singular e exige a mobilização de recursos específicos. Os casos são complexos e o seu compartilhamento, com a discussão das ações adotadas e condução, aprimora o trabalho de todos. Adicional mente, a escuta étão difícil quanto a revelação, pois mobiliza intensos sentimentos do profissional, tais como medo do agressor, raiva, desejos de vinganças. É preciso que esses sentimentos sejam sempre trabalhados na supervisão, cuja direção é retomar a perspectiva ético-política da não violência (não cabem, pois, revanches ou agressões reativas de qualquer espécie) e da adesão aos direitos humanos e das mulheres. Por todos esses motivos, a supervisão deve ser constante, assim como devem ser constantes as retomadas periódicas de sensibilização da Unidade e treinamentos dos profissionais do CONFAD.

Sendo apenasum acolhimento eorientação preliminares dos casos de violência, a esta atividade CONFAD segue-se a necessária relação da Unidade com os serviços que comporiam um conjunto mais especializado no trato às situações de violência, conjunto este que se esperaria operar em rede.

\section{A rede intersetorial de serviços}

Seno interior da Unidade de saúde énecessário que todos os profissionais trabalhem em equipe, com troca de informações e projetos comuns para o caso, projetos estes compartilhados e decididos pelas mulheres envolvidas, a atenção integral às mulheres em situação de violência não se esgota necessariamente no CONFAD, pois quase sempre demanda sua complementação. Pressupõe ainda o uso efetivo de uma ampla rede intersetorial, que propicie uma gama diversa de caminhos a partir 
do encontro realizado, com base nos projetos de vida que surgirem. Para isto, é fundamental, antes do início do trabalho, que exista um repertório ou um mapeamento da redeexistente, seja localmente, no território regionalizado da Unidade, seja no município a que pertence como um todo. Estemapeamento se dá em forma de guias de serviços e recursos locais. Em nosso caso, por meio de pesquisas específicas, foram publicados, para a região metropolitana de São Paulo, e, posteriormente, também para Recife e Porto Alegre, guias de serviçospara mulheres em situação deviolência em duas versões: uma de fácil porte para uso das mulheres ${ }^{29}$ e outra para uso dos profissionais ${ }^{30}$. A existência dos guias facilita o reconhecimento mútuo dos diferentes serviços da rede por parte de seus respectivos profissionais, bem como facilita 0 atendimento das mulheres, para que possam viabilizar suas necessidades. 0 simples conhecimento dos recursos já pode mudar a visão que cada uma tem da sua situação, retirando-a do isolamento e demonstrando, concretamente, o quanto o problema é coletivo, social e, assim, de todos, evidenciando a existência de políticas públicas eserviços montados para tal. Isto simboliza para todos que a afirmação dos direitos ea ética da não violência é um movimento cultural epolítico em curso ejáapoiado pelosorganismos governamentais, borrando o caráter estritamente privado que o senso comum vem forne cendo à violência doméstica, sobretudo.

Embora se aponteuma redeintersetorial, éfato que tal qualidade é ainda apenas potencial, isto é, há muitos obstáculos ainda para o efetivo trabaIho em rede. Uma primeira questão e que marca diferença com o setor saúde é que os serviços de saúde têm tradição de trabalho na forma de um sistema hierarquizado e, portanto, em níveis primário, secundário e terciário, dispostos de forma bidirecional, mas com uma porta de entrada definida, que é a atenção primária. No trabalho com violência, a redeéo modelo mais acei to pela literatura, e proposto; nele, a "entrada" pode se dar em qualquer ponto, sendo a circulação dos casos um trançamento entre os diversos pontos desse conjunto (os distintos serviços), entre os quais não há hierarquia de disposição e sim uma colocação horizontal nas relações entresi.

0 trabal ho em rede intersetorial guarda diversas tensões que devem ser superadas, a iniciar pe las diferentes definições e enquadres dados ao problema, tais como as instituições que trabalham com violência contra a mulher, com violência doméstica, com violência intrafamiliar, com violência sexual ou com violência de gênero. Também podem representar instituições tão diversas como abrigos, centros de referência geridos pelo poder municipal ou por ONGs, Delegacias de Defesa da Mulher, Fóruns, Procuradoria de Assistência Judiciária, serviços de saúde hospitalares e ambulatoriais, etc. Ademais, podem ser também instituições pertencentes a diversos conjuntos ou setores de produção social e de prestação de serviços distintos à população, como as instituições universitárias e as de setores assistenciais públicos ou privados ou do terceiro setor; as ligadas ao poder executivo federal, estadual ou municipal; ou, realizando ações do setor saúde, justiça, saúde, psicossocial, etc. Isto tudo sem esquecer que uma parte relevante do apoio é buscado em suportes familiares ou comunitários, os quais devem compor a rede de suporte social para as mulheres.

Se em cada um destes locais a violência é vista com um determinado recorte (como a doença, 0 crime, a miséria, o abuso de álcool e drogas, 0 conflito de gênero), eem cada um dos locais determinadas ações podem e devem ser realizadas, cada caso deve ser reintegrado em um todo pelo conjunto de profissionais e instituições, garantindo a possibilidade de um projeto assistencial comum. Tal qual já se estudou relativamente ao trabalho em equipe ${ }^{22}$, a integralidade do cuidado será produzida quando tivermos ações articuladas e interações entre os profissionais dessas ações, cujo resultado é a formulação interativa de projetos de intervenção que se potencializam em cada ponto da rede. Para isto, éimportante que, para além da operação do objeto parcelar de cada serviço, esteja presente em todos os serviços a consciência das outras ações acopladas e dos outros profissionais com quem haverá a interação, garantindo que a escuta interessada e a reflexão crítica estejam sempre presentes.

No entanto, as linguagens de cada um dos setores envolvidos são via de regra bastante distintos. Basta lembrar como médicos e enfermeiras descrevem seus casos, mesmo de atenção primária, em termos de sofrimentos e patologias, ecomparar esta com a maneira como advogados e delegados descrevem suas ocorrências, na linguagem do crime e da lei. Para que a comunicação possa ser estabelecida e o trabal ho ocorra em rede, éimportante operar traduções com a mulher usuária e entre os profissionais dos serviços envolvidos.

$\checkmark i a$ de regra, o reconhecimento mútuo é permeado de desconfianças quanto à qualidade do outro setor assistencial. Assim, profissionais de serviços de saúde desconfiam dos operadores do direito e educadores, enquanto na educação e justiça a visão dos serviços de saúde é de grande inoperância e falta de vagas. Superar esta desconfian- 
ça e refazer um pacto de trabalho, com apoio da gerência enível central, éfundamental para a finalidade de fortalecimento dos direitos humanos e emancipação

Fóruns intersetoriais, reuniões e supervisões internas aos serviços eà saúde, visitas aos serviços e contatos pessoais, listas de e-mails e telefones, tudo o que possa facilitar o contato é importante neste sentido. Em relação aos encaminhamentos, também se deve lembrar que o referenciamento precisa ser feito com cuidado (em termos do conhecimento das possibilidades assistenciais do outro local pela usuária e informações precisas sobrelocal ehorários e condições deatendimento) enão se tornar apenas uma forma de se "livrar" do caso, o que é dito pelos profissionais como "passar a batata quente". A existência deuma rede não pode significar a transformação de cada ponto dela em apenas um centro de triagem ou encaminhamento para os demais. 0 encaminhamento, quando couber, deve articular-sea uma resolução denível próprio, o que certamenteinclui empreendimentos do tipo CONFAD, na atenção primária do setor saúde. Além disto, é importante estabelecer mutuamente os fluxos e formas de referência e contrareferência de forma articulada às gerencias locais, para que não ocorram os fluxos baseados apenas em relações pessoais, que são descontinuados quando os profissionais trocam de posição nos serviços einstituições.

Por último, a maior dificuldade para lidar com a rede é sua fragilidade, instabilidade e dimensionamento dos diversos tipos de serviços, alguns em capacidade nitidamente inferior às necessidades. De um lado, sua fragilidade está dada no intenso movimento de fechamentos e aberturas de serviços, em boa parte devido ao fato de que as políticas públicas acabam sendo transformadas a cada novo governo, comprometendo a estabilidade e adensamento da rede. De outro, as propostas de abertura não necessariamente levam em conta os dimensionamentos dos casos, como estudos de prevalência, perfis de uso dos serviços pela possível clientela, etc.
Apesar das dificuldades, no entanto, as possibilidades de trabalho colocadas para lidar com a violência contra as mulheres da perspectiva de gênero para os serviços de saúde apontam para alternativas que aprimoram e levam em frente a organização dos serviços e a reflexão sobre suas finalidades $^{31}$. Enfatizando o respeito aos direitos humanos, a valorização da ética nas relações interpessoais e a emancipação de todos, combate-se de forma ativa a medicalização da violência, redirecionandose demandas que a princípio se esgotavam no interior dos serviços para alternativas para fora destes, transformando criticamente as necessidades em novas demandas mais ricas e diversificadas.

Por fim, queremos destacar os novos desafios que se colocam para o modelo implantado.

0 primeiro deles diz respeito à integração de um trabalho com crianças ehomens no CONFAD, desdea perspectiva degênero. Em relação às crianças, é comum que a violência doméstica envolvaas bem como aos adolescentes, como testemunhas ou vítimas diretas. A articulação do trabalho de proteção das crianças com o fortalecimento de seus responsáveis no sentido de superação da violência, que devem ser encaminhados ao CONFAD, é fundamental, além da percepção dos diferentes significados e riscos de violência a que estão expostos meninos e meninas. 0 trabalho com homens, na mesma perspectiva, ainda precisa ser implantado e monitorado.

0 segundo diz respeito à consolidação e articulação da rede, desde os fluxos internos à saúde até aqueles que integram os serviços de saúde à rede intersetorial, no sentido de sua quantidade, qualidade e reconhecimento mútuo.

Além disto, a notificação emonitoramento dos casos e ações de promoção e prevenção ainda são relativamente incipientes. São desafios que estão colocados para o futuro, e que só são possíveis hoje porque 25 anos de mobilização contra a violência contra a mulher produziram um volume suficientede conhecimento e políticas públicas que os possibilitam.

\section{Colaboradores}

AFPL d'Oliveira e LB Schraiber desenvolveram a proposta e o estudo do CONFAD, conceberam e redigiram 0 artigo igualmente; $\mathrm{H}$ Hanada e JG Durand participaram do desenvolvimento do CONFAD, da produção do material de campo eda redação final do artigo. 
1. Heise LL. Violence against women: an integrated framework. Violence against women 1998; 4(1):262-290.

2. Krug EG, Dahlber LL, M ercy JA, ZWI AB, Lozano R. World report on violence and health. Genebra: World Health Organization; 2002.

3. Campbell JC. Health consequences of intimate partner violence. Lancet 2002; 359(9314):1331-1336.

4. Schraiber LB, D'Oliveira AFPL, Falcão MTC, Figueiredo WS. Violência dói e não é direito - A violência contra a mulher, a saúde e os direitos humanos. São Paulo: UNESP; 2005.

5. Pinho AA, França-Junior I. Prevenção do câncer de colo do útero: um modelo teórico para analisar o acesso e a utilização do teste de Papanicolaou. Revista brasileira de saúde materna infantil 2003; 3(1):95-112.

6. Heise L, Ellsberg M, Gottemoeller M. Ending Violence Against Women. Population Reports 1999; 27(4):1-43.

7. Kiss LB, Schraiber LB. Temas médico-sociais e a intervenção em saúde: a violência contra mulheres no discurso dos profissionais. Cien Saude Colet [periódico na Internet]. [acessado 2009 jan 28]. Disponível em: http://www.abrasco.org.br/cienciaesaudecoletiva/artigos/artigo_int.php?id_artigo $=2407$

8. U.S. Preventive Services Task Force. Screening for Family and Intimate Partner Violence: Recommendation Statement. Annals of Internal M edicine 2004; 140(5):382-386.

9. Cole TB. Is Domestic Violence Screening Helpful? JAM A 2000; 284(5):551-553.

10. Colombini $M, M$ ayhew $S$, Watts $C$. Health-sector responses to intimate partner violence in low and middle-income settings: a review of current models, challenges and opportunities. Bulletin of the World health Organization 2008; 86(8):635-642.

11. Ayres JRCM. O cuidado, os modos de ser (do) humano e as práticas de saúde. Saúde e Sociedade 2004; 13(3):16-29.

12. Corrêa S, Ávila M B. Direitos sexuais e reprodutivos. Pauta Global e percursos brasileiros. In: Berquó $E$, organizadora. Sexo \& vida. Panorama da saúde reprodutiva no Brasil. São Paulo: Unicamp; 2003. p. 17-78.

13. Villela WV, Lago T. Conquistas e desafios no atendimento das mulheres que sofreram violência sexual. Cad Saude Publica 2007; 23(2):471-475.

14. Brasil. Ministério da Saúde. Área Técnica de Saúde da Mulher. Prevenção e tratamento dos agravos resultantes da violência sexual contra mulheres e adolescentes: norma técnica. $2^{2 a}$ ed. Brasília: M inistério da Saúde; 2005.

15. D'Oliveira AFPL, Schraiber LB. Identificando possibilidades e limites do trabalho em rede para a redução da violência contra a mulher: estudo entre três capitais brasileiras. In: SENASP. Relatório de pesquisa. Brasília: M inistério da Justiça; 2006.

16. Drezzet JF. Estudo de fatores relacionados com a violência sexual contra crianças, adolescentes e mulheres adultas [tese]. São Paulo (SP): Centro de Referência da Saúde da Mulher e de Nutrição, Alimentação e Desenvolvimento Infantil; 2000.

17. Schraiber LB, d'Oliveira AFPL, França-Junior I, Diniz S, Portella AP, Ludermir AB, Valença $O$, Couto $M T$. Prevalência da violência contra a mulher por parceiro íntimo em regiões do Brasil. Rev. Saude Publica 2007; 41(5):797-907.
18. Sarti CA, Barbosa RM, Suarez M M. Violência e gênero: vítimas demarcadas. Physis 2006; 16(2):167183.

19. Schraiber LB, D'Oliveira AFPL, Couto MT, Hanada $H$, Kiss LB, Durand JG. Violência contra mulheres entre usuárias de serviços públicos de saúde da Grande São Paulo. Rev. Saude Publica 2007; 41(3):359-367.

20. Vives-Cases C, Álvarez-Dardet C, Carrasco-Portiño $M$, Torrubiano-Domingues J. El impacto de la desigualdad de género en la violencia del compañero íntimo en España. Gac Sanit. 2007; 21(3):242-246.

21. Renner LM, Slack KS. Intimate partner violence and child maltreatment: Understanding intra - and intergenerational connections. Child abuse $\&$ neglet 2006; 30:599-617.

22. Peduzzi M. Equipe multiprofissional de saúde: conceito e tipologia. Rev. Saude Publica 2001; 35(1):103109.

23. M endes-Gonçalves RB. Tecnologia e Organização das Práticas de Saúde: características tecnológicas do processo de trabalho na rede estadual de Centros de Saúde de São Paulo. São Paulo: Hucitec; Rio de Janeiro: Abrasco; 1994.

24. Teixeira RR, O acolhimento num Serviço de Saúde Escola entendido como uma rede de conversações. In: Pinheiro R, M attos RA, organizadores. Construção da integralidade: cotidiano, saberes e práticas em saúde. Rio de Janeiro: IM S/BRASCO; 2003.

25. Schraiber $L$, d'Oliveira $A F P L, H$ anada $H$, Figueiredo W, Couto $M$, Kiss L, Durand J, Pinho A.Violência vivida: a dor que não tem nome. Interface - Comunic, Saúde, Educ. 2003; 7(12):41-54.

26. Oliveira $A R, D^{\prime}$ Oliveira AFPL. Violência de gênero contra trabalhadoras de enfermagem em hospital geral de São Paulo (SP). Rev. Saude Publica 2008; 42(5):868-876.

27. Sagot M. Ruta crítica de las mujeres afectadas por la violencia intrafamiliar en América Latina: estudios de caso de diez países. Washington, D.C.: PAH O; 2000.

28. Trapé CA. Mulheres em situação de conflito familiar e doméstico: avaliação do atendimento oferecido em um centro de saúde escola [monografia]. São Paulo (SP): Departamento de M edicina Preventiva/Faculdade de M edicina/Universidade de São Paulo; 2003.

29. M ini-guia de serviços. Mulheres em situação de violência. Departamento de M edicina Preventiva, 2001. São Paulo: Departamento de M edicina Preventiva, Faculdade de Medicina, Universidade de São Paulo; 2001.

30. Departamento de M edicina Preventiva. Faculdade de M edicina. Universidade de São Paulo. Mulheres em situação de violência: guia prático de serviços: município de São Paulo, 2002. 3ạ ed. São Paulo: Coletivo Feminista Sexualidade e Saúde/Centro de Saúde Escola S. B. Pessoa; 2002.

31. Brasil. Secretaria Especial de Políticas para as Mulheres. Enfrentamento à Violência contra a Mulher - balanço de ações 2006-2007. Braślia: Secretaria Especial de Políticas para as Mulheres; 2007.

Artigo apresentado em 19/11/2008

Aprovado em 03/12/2008

Versão final apresentada em 02/04/2009 